\title{
Tecnologia e trajetórias de internacionalização precoce: análise de casos na indústria brasileira
}

\section{Technology and precocious internationalization trajectories in the brazilian industry}

\author{
Andresa Silva Neto Francischini ${ }^{1}$ \\ João Furtado ${ }^{2}$ \\ Renato Garcia ${ }^{2}$
}

\begin{abstract}
Resumo: Este artigo analisa o processo de internacionalização de empresas nacionais dedicadas à produção de bens de maior densidade tecnológica. Elas apresentam diferentes motivações para a internacionalização, além das vantagens comerciais. O desenvolvimento de novas tecnologias resulta na adoção de trajetórias de internacionalização muito diferentes das que são observadas em outras empresas brasileiras. A pesquisa envolveu o estudo de três casos de empresas brasileiras que foram fundadas entre os anos de 1980 e 1990 e que se internacionalizaram precocemente: Bematech, Lupatech e Opto Eletrônica. Um importante aspecto comum entre essas empresas é que elas reconhecem a tecnologia como elemento central para o crescimento e expansão de suas atividades e investem continuamente em atividades de pesquisa e desenvolvimento. Isso contribui para o registro de patentes e desenvolvimento de produtos que podem ser adaptados de acordo com as necessidades de seus clientes nacionais e internacionais. Portanto, esse estudo trata de empresas que já nasceram com atributos que facilitam e até estimulam a internacionalização.
\end{abstract}

Palavras-chave: Internacionalização de empresas; Empresas de alta tecnologia; Organização industrial.

\begin{abstract}
This paper analyzes the internationalization process of national companies dedicated to the production of higher technological density goods. Besides commercial advantages, these enterprises present different motivations to internationalization. The development of new technologies results in the adoption of very different internationalization trajectories compared with those observed in other Brazilian companies. The research involved the study of three Brazilian companies which were founded between the eighties and nineties and became internationalized precociously: 'Bematech', 'Lupatech', and 'Opto Eletrônica'. An important common aspect among these companies is that they recognize technology as the main element for the growth and expansion of their activities, and invest continuously in development and research activities. This fact contributes to the application for patents and development of products that can be adapted according to the necessities of their national and international clients. Therefore, this study deals with companies that were already born with attributes that facilitate and stimulate internationalization.
\end{abstract}

Keywords: Internationalization of companies; Technological innovation; Industrial organization.

\section{Introdução}

As teorias clássicas que tratam sobre a internacionalização de empresas foram desenvolvidas a partir da análise de grandes empresas multinacionais americanas e europeias, em sua maioria, que já apresentavam forte presença nos mercados nacionais e se tornaram, a partir dessa posição, dominantes. Teorias como "Poder de Mercado" (Hymer, 1960, 1983) e "Ciclo de Vida do Produto" (Vernon, 1966, 1979) analisam o processo de internacionalização de empresas que, após o alcance de vantagens em seus mercados domésticos, passam a considerar a exploração de vantagens no mercado internacional por meio da internacionalização de suas atividades. Essas teorias não consideram, portanto, a análise de empresas criadas com foco em mercados internacionais desde o início de suas atividades.

A literatura brasileira está direcionada para a análise da internacionalização de empresas que já tinham conquistado vantagens competitivas no mercado doméstico antes da realização de investimentos

\footnotetext{
${ }^{1}$ Centro de Ciências Sociais e Aplicadas - CCSA, Universidade Presbiteriana Mackenzie, Campus Alphaville, Av. Mackenzie, 905, Tamboré, CEP 06460-130, Barueri, SP, Brasil, e-mails: andresa.francischini@mackenzie.br; andresaneto@gmail.com

${ }^{2}$ Departamento de Engenharia de Produção, Escola Politécnica, Universidade de São Paulo - USP, Avenida Professor Almeida Prado, 128, Cidade Universitária CEP 05508-070, São Paulo, SP, Brasil, e-mails: joao.furtado@ poli.usp.br; renato.garcia@poli.usp.br
} 
diretos no exterior. Esses investimentos tiveram como destino países da América Latina, principalmente, em decorrência da forte presença exportadora.

As empresas brasileiras de setores tradicionais se internacionalizaram muito tardiamente, após longas trajetórias de expansão doméstica. O universo dessas empresas era o Brasil e seu mercado - grande e protegido. A sua integração ao mundo externo deveu-se pelo elemento financeiro ou em épocas de crises domésticas, por meio de exportações que escoavam excedentes de produção (nos anos de 1981 a 1983, inclusive).

As empresas consideradas neste estudo apresentam diferenças importantes quando comparadas com a maioria das demais tratadas na literatura sobre internacionalização de empresas de países em desenvolvimento. São empresas de menor porte, fundadas mais recentemente e que desenvolveram a internacionalização precocemente em comparação com as tradicionais. De maneira geral, as empresas estudadas atuam em segmentos marcados por forte dinamismo e não chegaram a saturar as oportunidades de crescimento no mercado local antes de iniciarem o processo de internacionalização comercial, através da exportação para países desenvolvidos.

A contribuição deste estudo deve-se à identificação de uma lacuna na literatura que versa sobre uma nova abordagem para a internacionalização de empresas brasileiras, a partir da consideração da importância do desenvolvimento de produtos e serviços derivados de intensivos esforços para a criação de novas tecnologias e aplicações. Esses aspectos estão fortemente relacionados com as trajetórias de internacionalização das empresas estudadas.

A Figura 1 situa o tema de pesquisa considerado neste estudo:
Conforme ilustra a figura, essas empresas apresentam a importante característica de considerarem o desenvolvimento de novas tecnologia e aplicações como foco de suas atividades e elemento fundamental para seu crescimento e expansão. Desenvolvem produtos que podem ser adaptados de acordo com as necessidades e critérios de regulação de cada país. A internacionalização não tem foco apenas comercial, mas também contribui para o desenvolvimento de novas tecnologias e novas fontes de aprovisionamento de componentes. Ainda, as empresas estudadas não atuam em mercados de produtos de massa e grandes volumes, mas em segmentos com contornos técnicos bem definidos.

\section{Aspectos metodológicos}

O objetivo deste estudo é avaliar os processos de internacionalização de empresas brasileiras dedicadas à produção de bens e serviços com densidade e dinamismo tecnológicos. A trajetória de internacionalização será considerada a partir de suas dimensões comercial, produtiva, tecnológica e financeira. A questão investigada refere-se às razões que explicam por que há empresas brasileiras, dedicadas à produção de bens e serviços com densidade tecnológica, que não seguem a trajetória comum de expansão prioritária para o mercado doméstico e se internacionalizam precocemente.

Esta questão de investigação requer precisões adicionais. As empresas estudadas desenvolvem produtos (e por vezes serviços de apoio) que se destinam a mercados dinâmicos, caracterizados por uma rápida evolução das soluções e, portanto, por concorrência definida em intervalos curtos e padrões de oferta e demanda muito volúveis. Elas não seguem a trajetória

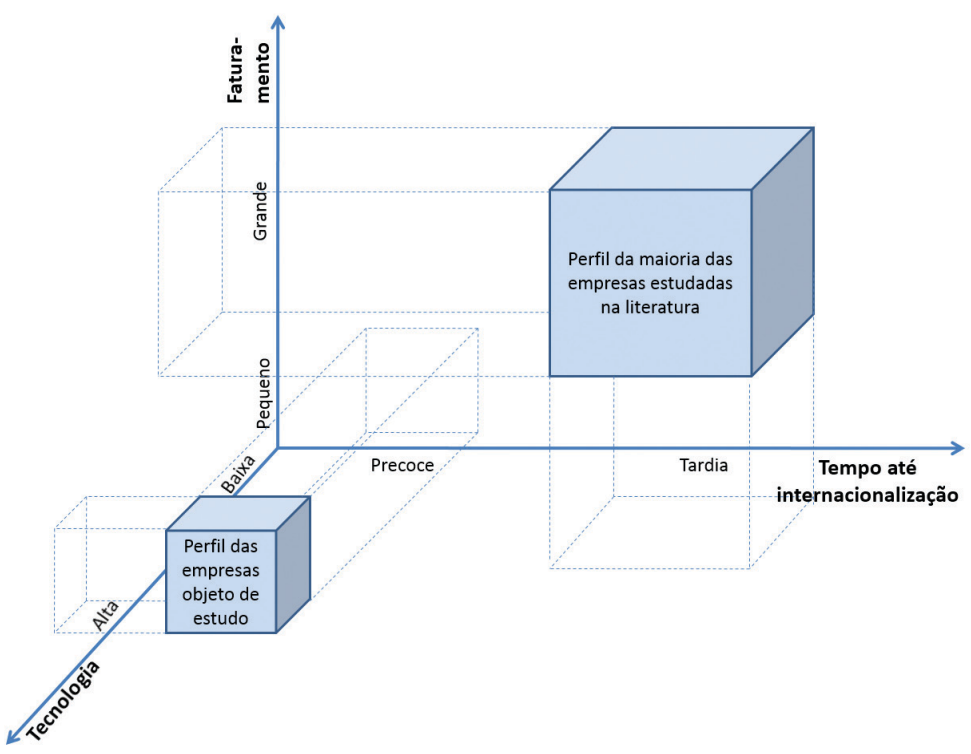

Figura 1. Contextualização da pesquisa. Fonte: Elaborada pelos autores. 
comum de internacionalização verificada na maioria das empresas brasileiras tratadas na literatura, que tem como principal característica o desenvolvimento parcial do processo de internacionalização, principalmente nas dimensões financeira, comercial (exportações) e tecnológica (importação de soluções), com presença muito tardia de unidades de produção no exterior. Além disso, o processo de internacionalização das empresas estudadas é considerado precoce em dois sentidos: (1) foi iniciado em uma etapa ainda inicial da história da empresa; e (2) antes de esgotar as fontes domésticas que alimentam o crescimento.

O estudo debruçou-se sobre três empresas: Bematech, Lupatech e Opto Eletrônica. A seleção considerou os seguintes critérios: (1) são empresas brasileiras ou de capital nacional; (2) todas foram fundadas entre as décadas de 1980 e 1990 e, portanto, enfrentaram períodos marcados pela instabilidade econômica; (3) os investimentos em P\&D em relação ao faturamento são superiores à média brasileira; (4) todas iniciaram o processo de internacionalização relativamente jovens, ou seja, após poucos anos de fundação; (5) as três empresas já consideravam desde a fundação o desenvolvimento de tecnologias para a expansão e crescimento; (6) a manutenção de subsidiárias no exterior não tem objetivo apenas comercial, mas também envolve o acesso às atividades de pesquisa por meio de parcerias com universidades e empresas.

A coleta de dados foi realizada em duas etapas. Inicialmente, foram consideradas fontes secundárias de informações sobre as empresas, a partir da análise de relatórios gerenciais, dossiês e artigos de jornais e revistas. Em seguida, foram realizadas entrevistas presenciais nas empresas selecionadas utilizando um roteiro de questões semiestruturadas. Nas três empresas, os entrevistados foram os fundadores e atuais presidentes das empresas.

$\mathrm{O}$ método de pesquisa utilizado foi o Estudo de Caso e foram formuladas três proposições para responder à questão investigada:

$1^{0}$ Proposição: As empresas estudadas possuem, comparativamente aos padrões brasileiros típicos, uma base tecnológica dotada de maior densidade e uma atuação em mercados mais dinâmicos, com renovação acelerada de produtos. Com isso, tiveram que desenvolver novos ativos tecnológicos e foram levadas a buscar bases mais amplas para amortizar os investimentos.

$2^{\circ}$ Proposição: Estas empresas são menores e iniciaram suas atividades em períodos econômicos marcados por fortes instabilidades e conjunturas erráticas. Esses fatores induziram a internacionalização dessas empresas ainda jovens, como uma forma de contornar ou superar as adversidades.
$3^{0}$ Proposição: A internacionalização dessas empresas ocorreu de forma gradual e favoreceu a presença em mercados mais próximos.

Portanto, a partir dessas considerações metodológicas, tem-se o desenvolvimento do estudo. A seguir, é feita a apresentação das teorias clássicas e das abordagens recentes que tratam da internacionalização de empresas. As principais características que envolvem o processo de internacionalização de empresas brasileiras também são apresentadas.

\section{Referencial teórico}

\subsection{O conceito de internacionalização: teorias clássicas e abordagens recentes}

Esta seção apresenta as principais teorias desenvolvidas para a análise dos processos de internacionalização e desenvolvimento de empresas internacionais, a partir da consideração dos principais autores que estudam o tema. Primeiramente tem-se a apresentação das teorias clássicas, desenvolvidas a partir de 1960 e, em seguida, são consideradas as abordagens recentes para o tema. Hymer (1960) foi um dos primeiros autores a pesquisar o processo de internacionalização de empresas a partir da investigação das operações internacionais formalizadas em diferentes países. $\mathrm{O}$ autor desenvolveu a Teoria do Poder de Mercado.

Ao analisar a influência do comércio internacional no desenvolvimento das operações internacionais, Hymer (1960) destaca que as empresas frequentemente desenvolvem operações internacionais em países em que o comércio internacional é ou foi importante, representando uma estratégia de substituir exportações ou de gerar importações. Portanto, considerando a Teoria do Poder de Mercado, é possível concluir que a formalização de operações internacionais por parte de empresas nacionais é uma maneira de explorar, no mercado internacional, vantagens já conquistadas no mercado local.

Inicialmente, a empresa introduz a inovação e o produto exibe uma elevada taxa de crescimento, se é crescente o número de consumidores que passam a usá-lo. A partir da saturação do mercado, a rentabilidade começa a apresentar declínio e ao mesmo tempo outras empresas entram no mercado e podem passar a dominar os custos de produção. Como forma de defesa, a empresa passa a concentrar constantes esforços para o desenvolvimento de novos produtos e prolongamento do ciclo do produto, através do controle dos canais de comercialização, desenvolvimento de pesquisa e busca por lugares que apresentam baixos custos de mão de obra (Hymer, 1983).

Vernon (1966) desenvolveu a Teoria do Ciclo de Vida do Produto e suas análises partem da hipótese de que todos os países desenvolvidos têm igual acesso aos avanços da ciência e do conhecimento, 
ainda que afirme que essa igualdade de acesso não garante a aplicação dos novos conhecimentos no desenvolvimento de novos produtos de forma equânime. Vernon (1979) ressalta que as inovações são desenvolvidas no mercado doméstico em que está localizada a firma.

No entanto, o autor destaca que as inovações desenvolvidas em mercados locais tendem a considerar as características destes mercados, o que aumenta as chances de que as atividades de produção também sejam desenvolvidas localmente, como forma de minimizar custos de transporte. Somente na fase de maturação do produto, novas firmas passam a atuar no mercado e, como resultado de maior concorrência, surge a necessidade de diferenciação. Ao término desse estágio, a demanda pelo novo produto tende a aumentar e a empresa passa a considerar a possibilidade de padronização.

Conforme a empresa exporta seus produtos para outros países, os empresários passam a avaliar a possibilidade de estabelecer atividades de produção no exterior. $\mathrm{O}$ autor destaca que essa decisão depende da capacidade de previsão dos custos de produção no determinado país, onde os custos dos fatores de produção e a tecnologia empregada são diferentes (Vernon, 1966). Isto explica a opção de algumas empresas internacionais por países menos desenvolvidos para estabelecimento de suas atividades de produção. Da mesma maneira, se os custos de mão de obra em determinado país superam os custos de transporte, a empresa tende a optar pela exportação de seus produtos para tal país.

Dunning $(1980,1993,1997)$ analisa o processo de internacionalização das empresas a partir do estabelecimento de unidades de produção no exterior. $\mathrm{O}$ autor reforça que o objetivo das empresas é a transformação de insumos em produtos de maior valor, através de processos de produção. Os insumos, por sua vez, podem ser classificados em duas categorias:

a) Insumos específicos de localização: podem ser adquiridos por todas as firmas mas, apesar da disponibilidade, apresentam localização específica. Como exemplo, o autor considera o trabalho, a proximidade com o mercado e os ambientes legal e comercial.

b) Insumos específicos de propriedade: podem ser desenvolvidos pela própria empresa ou adquiridos, como habilidades organizacionais e tecnologias. Esta categoria de insumos, que envolve patentes e marcas, é protegida por direitos de propriedade, porém seu uso não é tão restrito como os insumos específicos de localização.
A posse destes ativos pelas firmas contribui para a criação de vantagens que influenciam o estabelecimento de atividades de produção no exterior. Deste modo, a posse de "vantagens de propriedade" por uma firma influencia a escolha do mercado internacional em que irá atuar, do mesmo modo que a existência de "vantagens de localização" é um aspecto importante para a definição da forma mais adequada para a atuação no mercado escolhido, o que envolve as opções de exportação ou produção direta no exterior (Dunning, 1980).

A opção pela produção no exterior por parte de uma firma considera, portanto, a existência de três grupos de vantagens: Propriedade (Ownership), Localização (Location) e Internalização (Internalization), que juntas compõem o Modelo OLI, definido no "Paradigma Eclético da Produção Internacional" desenvolvido por Dunning (1980).

Já o Modelo de Uppsala tem como principal característica a análise dos processos de internacionalização de empresas a partir de aspectos organizacionais, no qual a firma é a unidade de análise. Diferentemente das teorias apresentadas anteriormente, o foco das considerações teóricas não se constitui nos aspectos macroeconômicos relacionados ao comércio internacional.

O objetivo do modelo é analisar o processo de internacionalização da firma considerando como foco o seu desenvolvimento individual, de maneira mais precisa, o uso do conhecimento sobre mercados e operações, conquistado a partir da expansão das operações da firma em mercados individuais. $\mathrm{O}$ conhecimento sobre o mercado internacional é adquirido a partir da experiência em atuar em mercados internacionais, porém sua falta é considerada um obstáculo importante para o desenvolvimento de operações internacionais pela firma (Johanson \& Vahlne, 1977, 1990).

A atuação de empresas no exterior pode ser influenciada pela atuação em redes, ou seja, relacionamentos estabelecidos com outras empresas. Assim, a partir desses relacionamentos, há trocas de produtos e serviços mas também de conhecimento e informação entre as empresas participantes. Desse modo, a participação em redes pode ser entendida como importante investimento para as empresas, capaz de gerar vantagens organizacionais (Vahlne \& Johanson, 2013).

O processo de internacionalização da firma pode evoluir em quatro estágios: (1) Desenvolvimento de exportações não regulares; (2) Desenvolvimento de exportações utilizando-se de agentes de representação; (3) Estabelecimento de uma subsidiária dedicada a vendas; e (4) Estabelecimento de uma unidade de produção. Ainda, as firmas optam por países em que prevalece menor "distância psíquica" em seus processos de internacionalização, o que facilita o 
conhecimento de mercado e experiência. O conceito de "distância psíquica" envolve aspectos como idioma, nível educacional, práticas comerciais, cultura e desenvolvimento industrial que podem variar entre os países (Johanson \& Vahlne, 1977, 1990).

Andrade \& Galina (2013) analisam os processos de internacionalização de empresas multinacionais de países em desenvolvimento e concluem que o desempenho negativo de algumas empresas pode estar relacionado a fatores como a falta de experiência em mercados internacionais, bem como a falta de familiaridade com aspectos culturais de outros países e de experiência global dos gestores, entre outros.

Nos anos recentes, o surgimento de novos processos de internacionalização levou ao desenvolvimento das abordagens recentes para o tema. Cantwell (1989) e Cantwell \& Piscitello (1999) afirmam que a diversificação e a internacionalização podem ser reconhecidas como partes de um mesmo processo. A presença dos produtos de uma firma em diversos mercados é entendida como uma maneira de explorar as competências já estabelecidas de maneira mais eficiente, enquanto o desenvolvimento de novas tecnologias é considerado como criação de novas competências. Nesse sentido, baseado na abordagem de Penrose (1956), a firma é definida como um conjunto de recursos, capaz de criar novas competências e de consolidar suas capacidades (Cantwell \& Piscitello, 1999).

A partir dos estudos de Penrose (1956), é possível considerar a internacionalização como uma das dimensões da diversificação. Uma firma pode ofertar produtos diferentes em novos mercados geográficos por meio da atual base tecnológica, bem como criar novos produtos a partir de bases tecnológicas diferentes desenvolvidas por meio de novas competências na área tecnológica.

A Figura 2 representa as três formas de diversificação definidas por Penrose (1956). A firma pode ingressar em novos mercados, inclusive internacionais, com os mesmos produtos e mesma base tecnológica, o que é representado na figura se a firma passar do ponto A para o ponto D. A expansão das atividades da firma para novos produtos voltados para o mesmo mercado e desenvolvidos a partir de uma mesma base tecnológica pode ser representada pela passagem dos pontos C para D. Finalmente, a firma pode optar pela diversificação através de novas bases tecnológicas destinadas para os mesmos mercados e comercializando os mesmos produtos, o que é representado na figura pela passagem dos pontos B para D.

Essa nova dimensão da diversificação também pode ser alcançada por meio da aquisição de empresas. As expectativas presentes entre os consumidores do país local podem ser desenvolvidas entre os consumidores localizados em outros países, cenário que tende a favorecer a oferta de novos produtos em mercados locais e internacionais. Da mesma maneira, a internacionalização pode ser entendida como um meio de reduzir os impactos das flutuações da demanda no mercado local.

Chesnais (1996) analisa o processo de internacionalização de empresas a partir da consideração de três dimensões: o intercâmbio comercial, o investimento produtivo no exterior e os fluxos de capital monetário ou capital financeiro. Diferentemente de Hymer (1960), o autor considera que o desenvolvimento de atividades de exportação

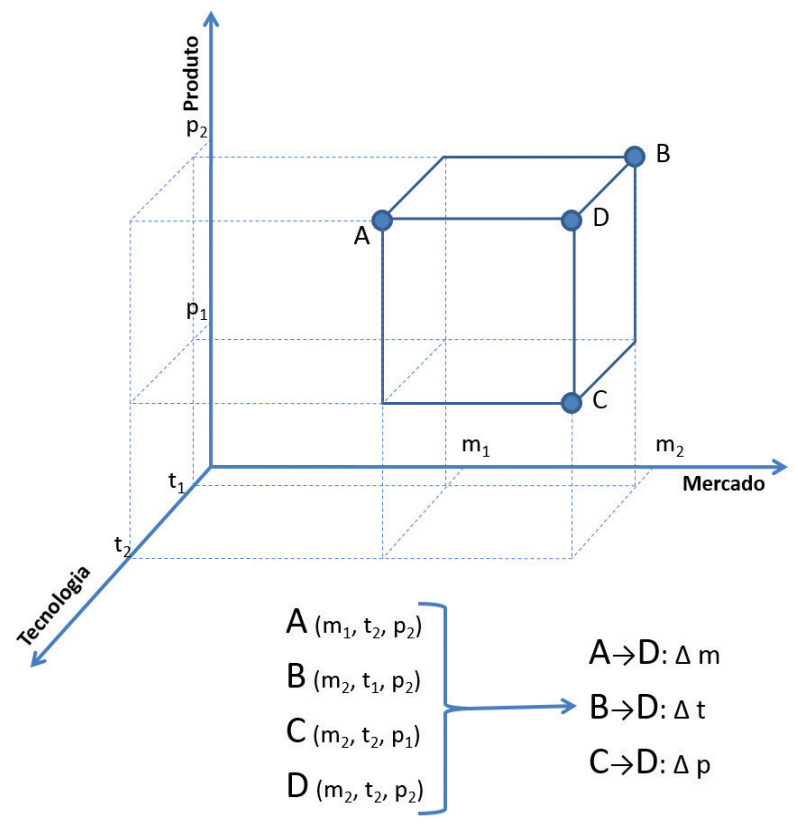

Figura 2. Internacionalização e diversificação. Fonte: Elaborada pelos autores. Baseada em Penrose (1956). 
é uma das dimensões do processo, definida como "internacionalização comercial". Outras dimensões possíveis são a "internacionalização produtiva", caracterizada pelo estabelecimento de unidades de produção no exterior e a "internacionalização financeira", caracterizada pela intensificação de fluxos de capital financeiro entre os países. Essas três dimensões do processo de internacionalização estão presentes entre empresas multinacionais.

Porém, a partir da evolução das atividades desenvolvidas pelas empresas no exterior, Chesnais (1996) destaca o surgimento de outra dimensão para o processo de internacionalização, baseada nos ativos intangíveis das empresas e no capital humano, definida como "internacionalização tecnofinanceira". Essa dimensão está baseada na criação de know-how e atividades de pesquisa e desenvolvimento.

Evidentemente, tanto Chesnais (1996) quanto a maioria dos autores que contribuíram nesse campo tratavam (explícita ou implicitamente) de grandes empresas ou grandes grupos empresariais. $\mathrm{O}$ fenômeno é antigo e sem dúvida muito importante, mas o objeto deste artigo é a internacionalização precoce de empresas de dimensões muito menores.

Outra abordagem mais recente sobre o tema da internacionalização de empresas define-se como Born Global. O conceito apresenta muitas diferenças quando comparado às teorias tradicionais, que tratam a internacionalização como um processo a ser desenvolvido em etapas, de maneira incremental (Madsen \& Servais, 1997). O termo é utilizado para definir uma firma que, desde a fundação ou após pouco tempo de fundada, considera a atuação global em suas estratégias de desenvolvimento. Knight \& Cavusgil (2004) definem uma firma "Born Global" como aquela que adota a internacionalização em períodos curtos após a fundação. Os autores destacam que a entrada em mercados internacionais é feita em um período de até três anos.

As novas abordagens para o estudo da internacionalização de empresas representam um novo caminho para a análise de casos em que as teorias clássicas não se mostram adequadas ou não são capazes de explicar os fenômenos em sua totalidade, principalmente quando empresas brasileiras e seus processos de internacionalização estão sendo considerados.

\subsection{Internacionalização de empresas brasileiras}

O debate brasileiro sobre a internacionalização de empresas nacionais ganhou amplitude nos últimos anos. Os autores que analisam o tema partem de diversas perspectivas e as empresas brasileiras têm sido estudadas com enfoques diferenciados. A adoção de estratégias de internacionalização por parte de empresas brasileiras é um processo tardio, principalmente quando comparado com os de outros países emergentes. Entre as décadas de 1960 e 1970, as atividades de internacionalização estavam concentradas em exportações, enquanto, no final da década de 1970 e início dos anos 1980, um pequeno número de empresas brasileiras havia realizado investimentos diretos no exterior (Barreto \& Rocha, 2003; Rocha et al., 2007; Fleury \& Fleury, 2007).

Quanto ao aspecto da internacionalização tardia, Ricupero \& Barreto (2007) destacam que o processo de internacionalização de empresas nacionais foi iniciado em um cenário econômico marcado pelo baixo crescimento, principalmente durante a década de 1980. A realização de investimentos diretos externos a partir da década de 1990 pode ser entendida como um caminho para manter o dinamismo alcançado internamente em períodos anteriores e, neste sentido, seria análogo a outros processos de internacionalização tratados nas teorias clássicas, como na Teoria do Ciclo do Produto, desenvolvida por Vernon (1966). Nesse sentido, as empresas buscavam a internacionalização na fase em que o produto já havia conquistado a massificação no mercado interno.

Quanto à categoria de internacionalização adotada pela maioria das empresas brasileiras, Silva (2003) afirma que a internacionalização de empresas de capital nacional era essencialmente comercial, ou seja, baseada em exportações. Somente a partir da década de 1970, um pequeno número de empresas brasileiras passou a adotar estratégias de internacionalização produtiva com o objetivo de alcançar mercados em que o País já tinha forte presença exportadora. Ricupero \& Barreto (2007) também ressaltam a existência de uma estreita correlação entre o estabelecimento de relações comerciais e a realização de investimentos diretos no exterior por empresas nacionais.

Para Arbix et al. (2005), de maneira geral, o estabelecimento de subsidiárias no exterior pode influenciar positivamente o desempenho exportador de empresas, uma vez que contribuem para o acesso aos canais de comercialização, para a adaptação dos produtos em mercados específicos, além de favorecer o acesso a recursos financeiros e apropriação de tecnologias. A maioria das empresas brasileiras passaram a desenvolver atividades de produção no exterior por meio da realização de Investimentos Diretos Externos (IDE) apenas recentemente, a partir de 1990 (Rocha et al., 2007; Laplane \& Sarti, 1999). Esses investimentos têm sido caracterizados pelo estabelecimento de unidades próprias no exterior, aquisições de outras empresas e ainda por meio do estabelecimento de joint ventures (Fleury \& Fleury, 2007).

Quanto aos tipos de investimentos no exterior realizados por empresas brasileiras, Silva (2003) destaca que eles têm sido caracterizados pelo 
estabelecimento de unidades produtivas, escritórios comerciais e serviços de assistência técnica. Independentemente da forma, a autora destaca que esses investimentos são realizados com o objetivo de garantir ou ampliar as exportações. Silva (2003) considera ainda que a localização também é explicada a partir da internacionalização comercial, ou seja, as empresas buscam realizar investimentos em países que já representam importantes mercados para seus produtos. Rocha et al. (2007) destacam que muitos dos investimentos em internacionalização desenvolvidos por empresas brasileiras têm como destino países da América Latina.

Apesar de o modelo de internacionalização predominante entre empresas de capital nacional ser a categoria comercial, Coutinho et al. (2008) consideram que a formalização de investimentos diretos no exterior será parte intrínseca e, possivelmente, fundamental para o desenvolvimento da economia brasileira nos próximos anos. Para tanto, os autores elegem como principal fator o amadurecimento da competitividade das empresas brasileiras que se beneficiam da forte expansão do comércio mundial. Neste sentido, a internacionalização das atividades possibilita a uma empresa brasileira participar como global player, estabelecendo relações com fornecedores, clientes e competidores internacionais.

A adoção da internacionalização como meio de ultrapassar barreiras comerciais é uma das motivações mais antigas consideradas pelas grandes empresas de manufatura europeias e norte-americanas. Inclusive, esta foi a motivação para o estabelecimento de empresas no Brasil e em outros países da América Latina no século XIX (Ricupero \& Barreto, 2007).

Apesar da identificação e classificação das principais motivações para a internacionalização, é importante salientar que elas podem interagir simultaneamente de acordo com o grau de internacionalização da empresa considerada. Além disso, os fatores motivacionais para a formalização de IDE têm como cenário as mudanças nas condições de concorrência que marcam o período recente (Coutinho et al., 2008). Para Cyrino et al. (2010), além da busca por economias de escala, a preocupação com a concorrência global, a saturação do mercado doméstico e a busca pelo melhor atendimento aos clientes internacionais destacam-se entre as motivações para a internacionalização de empresas brasileiras.

A partir dos aspectos considerados, é possível concluir que o processo de internacionalização de empresas brasileiras foi iniciado tardiamente, pois, apenas a partir da década de 1990, as empresas passaram a considerar, de maneira mais intensa, a realização de investimentos diretos no exterior. As exportações tiveram um papel importante nesse processo já que as empresas buscavam a realização de IDE em regiões nas quais mantinham relações comerciais há algum tempo. A localização mais comum dos investimentos no exterior era em países da América Latina, devido, principalmente, ao desempenho da internacionalização comercial das empresas por meio das exportações.

\section{Descrição geral das empresas estudadas}

Essa seção apresenta o histórico e dados sobre as empresas estudadas: Bematech, Lupatech e Opto Eletrônica. A intenção é contribuir para a compreensão da trajetória de desenvolvimento dessas empresas e, assim, contextualizar a internacionalização. Para isso, apresentamos elementos do histórico das empresas e dados econômico-financeiros.

A Bematech S/A foi fundada em 1990 em Curitiba por Wolney Betiol e Marcel Malczewski. A matriz está localizada em São José dos Pinhais, região metropolitana de Curitiba, e o laboratório de Pesquisa e Desenvolvimento, em Curitiba. A empresa mantém filiais na Bahia (Salvador), Goiás (Goiânia), Amazônia (Manaus), Minas Gerais (Belo Horizonte), Pernambuco (Recife), São Paulo (São Paulo e Ribeirão Preto), Rio de Janeiro (Rio de Janeiro), Rio Grande do Sul (Porto Alegre), Santa Catarina (São José), Paraná (Curitiba). Além disso, mantém unidades comerciais no Brasil (Bematech Latinoamerica Brasil, em São Paulo) e subsidiárias no exterior (Estados Unidos, Alemanha, Taiwan e Argentina). O foco de atuação da empresa Bematech é a automação comercial, pela oferta de hardware e software. O valor do faturamento em 2013 é quase vinte vezes maior que o alcançado em 1994, em termos reais.

A Lupatech iniciou suas operações em agosto de 1980, na cidade de Caxias do Sul, Estado do Rio Grande do Sul. No ano de 1993, passou a ter a denominação atual, Lupatech S.A. Em 2008, a empresa empregava cerca de 3.200 funcionários distribuídos em suas unidades no Brasil e no exterior. As atividades desenvolvidas pela empresa estão classificadas em três segmentos: Energy Products, Flow Control e Metal.

No primeiro segmento, Energy Products, estão concentradas as atividades operacionais para a manutenção e desenvolvimento de infraestrutura para a indústria de petróleo e gás. Os principais produtos são cabos para ancoragem de plataformas em águas profundas, válvulas, equipamentos para exploração de poços, revestimentos de tubos, compressores para gás, sensores e serviços.

O segundo segmento, Flow Control, dedica-se à produção e comercialização de válvulas para as indústrias química, farmacêutica, papel e celulose e construção civil. Já o terceiro segmento, definido como Metal, desenvolve e produz peças, partes complexas e subconjuntos a partir de processos de fundição de precisão e de injeção de aço para a indústria 
automotiva mundial. Este segmento dedica-se ainda à fundição de peças em ligas metálicas resistentes à corrosão para os setores de válvulas industriais e bombas utilizadas, principalmente, em processos desenvolvidos pela indústria de petróleo e gás. Desde a fundação, a Lupatech tem adquirido empresas no Brasil e no exterior como forma de fortalecer sua posição em cada segmento de atuação. Depois do ano de 2006, a Lupatech passou a atuar também no segmento Energy.

A Opto Eletrônica foi inaugurada em 27 de outubro de 1986. Atualmente a empresa emprega mais de 300 funcionários e sua sede está localizada na cidade de São Carlos, interior do Estado de São Paulo. A Opto atua, desde sua fundação, na produção de componentes ópticos e filtros azuis para utilização odontológica. O objetivo inicial da empresa era a produção do primeiro laser industrial em escala no Brasil e hoje a empresa também desenvolve aplicações industriais para os lasers Hélio-Neônio que fabrica. O desenvolvimento de tecnologias a laser permite à empresa atuar na área médica, especialmente oftalmologia, e também na produção de componentes ópticos para utilização aeroespacial.

As atividades de produção da Opto são desenvolvidas no Brasil e estão distribuídas em seis divisões, dedicadas aos seguintes produtos e serviços: (1) Divisão Médica Oftalmológica; (2) Divisão Odontológica; (3) Divisão Antirreflexo; (4) Divisão Industrial; (5) Divisão Componentes Ópticos; (6) Divisão Aeroespacial. A Opto Eletrônica apresentou crescimento acumulado, em termos reais, de mais de $1.000 \%$ entre os anos de 1994 e 2010.

A Opto possui unidades comerciais no Brasil e no exterior. A Opto Latin America está localizada na cidade de São Paulo e dedica-se ao desenvolvimento de distribuidores e a atividades de suporte para produtos da Divisão Médica Oftalmológica na América Latina. No exterior, a empresa mantém as subsidiárias Opto USA (Estados Unidos), Opto Global (Austrália) e Opto Components (Áustria), dedicadas ao acompanhamento das tendências para o setor em que a empresa atua, ao desenvolvimento de parcerias em pesquisas e ao estabelecimento e fortalecimento de suas atividades comerciais nos mercados nacional e internacional.

\section{Apresentação dos resultados e comparação com as teorias de internacionalização}

\subsection{Atividades de pesquisa e desenvolvimento}

Os esforços contínuos realizados em atividades de Pesquisa e Desenvolvimento (P\&D) por parte das empresas consideradas neste estudo têm papel importante na trajetória de crescimento e internacionalização. Desde a fase de fundação, a Bematech, a Lupatech e a Opto Eletrônica têm desenvolvido intensamente atividades de pesquisa desde que atuam em mercados em que a renovação dos produtos ocorre em curtos intervalos de tempo. Além disso, seus produtos e serviços exigem conhecimentos científicos e tecnológicos em doses relativamente mais elevadas do que na indústria de modo geral.

A empresa Bematech mantém o Laboratório de Pesquisa e Desenvolvimento na cidade de Curitiba. As atividades desenvolvidas são classificadas em quatro grupos assim organizados: (1) Segmento de impressoras; (2) Área de ODM (Original Design Manufacturer: responsável pela gestão dos processos de desenvolvimento e de manufatura de produtos da Bematech por terceiros); (3) Software; e (4) Engenharia de Produtos. A Lei de Informática tem contribuído para o desenvolvimento da área de pesquisa e desenvolvimento da Bematech. Desde 2001, a empresa tem formalizado investimentos anuais superiores aos solicitados pela lei, para as atividades de pesquisa e desenvolvimento de produtos para automação bancária e comercial.

Entre os anos de 2003 e 2006, a Lupatech investiu cerca de US\$5 milhões em pesquisa e desenvolvimento. Neste período, no ano de 2005, foi criado o Centro de Pesquisa e Desenvolvimento Lupatech (CPDL), no Rio Grande do Sul, com o objetivo de desenvolver processos e produtos a partir de inovações tecnológicas.

A área de pesquisa e desenvolvimento da Opto Eletrônica está localizada na cidade de São Carlos, sendo denominada Divisão de Pesquisa \& Desenvolvimento. Além da criação de novos produtos para a empresa, a Divisão de P\&D também desenvolve produtos e aplicações para terceiros, a partir da utilização das tecnologias desenvolvidas pela Opto nas seguintes áreas: ótica de precisão, filmes finos especiais, aplicações médicas e industriais a laser e no segmento aeroespacial. É também responsabilidade dessa divisão o desenvolvimento de adaptações e melhorias nos produtos a laser, como forma de atender seus variados clientes.

A análise comparativa das informações das três empresas estudadas possibilita a identificação dos seguintes pontos em comum entre elas:

1. As empresas desenvolvem, desde a fundação ou mesmo antes, atividades de pesquisa e desenvolvimento: as atividades de $\mathrm{P} \& \mathrm{D}$ são desenvolvidas em laboratórios no Brasil e, desde o início, são reconhecidas como fundamentais para o crescimento e desenvolvimento das empresas. Além disso, as áreas de P\&D contam com funcionários altamente qualificados, sendo que muitos com mestrado e doutorado. Os 
empresários entrevistados são pessoas altamente qualificadas, em termos de suas trajetórias acadêmicas prévias, de experiência empresarial e, muitas vezes, forte experiência internacional.

2. Com relação à porcentagem do faturamento dedicada a atividades de P\&D, a empresa que investe a maior porcentagem é a Opto Eletrônica (10\%), seguida pela Bematech $(6,5 \%)$ e, por último, a Lupatech (1,5\%). Essas porcentagens são explicadas, em grande maioria, pelas características dos produtos e serviços desenvolvidos por cada empresa e estão acima da média para a indústria brasileira. De acordo com dados do Instituto Brasileiro de Geografia e Estatística (IBGE, 2005), no ano de 2003, apenas $9,9 \%$ das empresas industriais brasileiras podiam ser classificadas como de alta intensidade tecnológica. Essas empresas investiam entre $0,96 \%$ e $2,72 \%$ do faturamento em atividades de Pesquisa e Desenvolvimento. Essa porcentagem é expressiva no contexto brasileiro e, principalmente, nos setores de atuação dessas empresas.

3. As empresas contam com o apoio de recursos financeiros disponibilizados por órgãos governamentais para o desenvolvimento das atividades de P\&D: a compra dos primeiros equipamentos da Opto Eletrônica foi viabilizada através de uma linha de financiamento da Financiadora de Estudos e Projetos (FINEP) e de recursos do Programa de Apoio à Capacitação Tecnológica da Indústria (PACTI), totalizando US\$1 milhão (Ribeiro, 2001).

Para o desenvolvimento dos tratamentos antirreflexo no Brasil, a empresa contou inicialmente com apoio da FINEP. Desde 2008, a Opto tem trabalhado no desenvolvimento de novos produtos, como o "Klink", que permite a recuperação de córneas. Muitos desses projetos na área de oftalmologia contam com recursos da FINEP.

No caso da Lupatech, a abertura do CPDL exigiu investimentos de cerca de $\mathrm{R} \$ 10$ milhões. Cerca de $80 \%$ desse valor teve origem em recursos financiados pela FINEP. Segundo Goldbaum (2001, p. 8), ao iniciar o processo de diversificação de suas atividades, entre os anos de 1994 e 1995, a Bematech pôde contar com recursos do Banco Nacional do Desenvolvimento (BNDES). Em 2007, o BNDES tornou-se mais um acionista da empresa. Inicialmente, a empresa não contou com recursos da FINEP. Porém, a Lei da Informática, criada pelo governo em 2001, teve impactos positivos no desenvolvimento da empresa.
4. As empresas atuam em mercados em que a renovação dos produtos é acelerada. Nesse cenário, os investimentos contínuos em atividades de pesquisa e desenvolvimento e no acompanhamento das tendências nos setores em que atuam são fundamentais para a continuidade de suas atividades.

A Opto Eletrônica reconhece que o mercado em que atua é marcado por forte dinamismo. $\mathrm{O}$ ciclo de vida médio considerado para seus produtos é de cerca de três anos e a forte presença internacional reforça a necessidade de renovação constante. Da mesma maneira, a Bematech reconhece que, no setor em que a empresa atua, a transição tecnológica é muito rápida, ou seja, se a empresa não for capaz de absorver rapidamente as novas tendências para o setor, provavelmente perderá seus mercados para a concorrência. Para tanto, a manutenção de subsidiárias no exterior, especialmente na Ásia e Europa, dedicadas ao acompanhamento das principais tendências, têm papel fundamental para o desenvolvimento da empresa. Para a Lupatech, em geral, cada produto tem uma finalidade de acordo com a necessidade do cliente. Os produtos passam por adaptações de acordo com o uso e a área de pesquisa e desenvolvimento, concentrada no Brasil, deve ser capaz de adequar os produtos às necessidades de cada cliente.

5. As empresas desenvolvem parcerias em atividades de pesquisa e desenvolvimento no exterior. Essas parcerias têm contribuído para os avanços tecnológicos nas áreas de atuação das empresas, pois possibilitam o desenvolvimento de novas tecnologias bem como aplicações em novos produtos e processos. Para a Opto, essas parcerias são estabelecidas com universidades, governos e empresas no exterior e são consideradas fundamentais para o desenvolvimento da empresa e para a conquista de mercados no exterior.

Para a Bematech, as subsidiárias no exterior também desempenham um importante papel para a área de P\&D, pois possibilitam o acompanhamento das tendências desenvolvidas em diferentes países e relacionadas com os produtos da empresa. Já a Lupatech, ao adquirir empresas no exterior, mantém as estruturas de pesquisa e desenvolvimento bem como os laboratórios implantados pelas subsidiárias. A empresa reconhece que, principalmente no segmento de energia, as empresas internacionais adquiridas contribuem para os avanços tecnológicos alcançados pela Lupatech, pois possibilitam o acesso a linhas de produtos e serviços complementares. 
6. As três empresas estudadas têm formalizado pedidos para registros de patentes. A Opto Eletrônica apresentou 17 pedidos de registros de patente junto ao INPI, sendo o primeiro formalizado cerca de dois meses após sua fundação. A Bematech conta com 10 registros de patentes apenas no Brasil. Esses registros tiveram início em 1994, após quatro anos do início das operações da empresa. Já a Lupatech conta com 17 pedidos para registros no Brasil, sendo o primeiro formalizado em 1998. Tanto a Bematech quanto a Lupatech contam com registros de patentes no exterior, obtidos a partir da aquisição de empresas internacionais.

Finalmente, é possível concluir que as três empresas estudadas apresentam características importantes que as destacam das empresas tradicionais brasileiras. Todas as empresas empregam uma porcentagem do faturamento em atividades de pesquisa e desenvolvimento. A razão principal é a consideração da importância dessa área pelos dirigentes das três empresas, já que reconhecem que o crescimento da empresa é dependente da capacidade de desenvolvimento de novas tecnologias e de novas aplicações entre os produtos e serviços.

A área de P\&D tem papel fundamental na internacionalização das empresas consideradas. Para os presidentes das três empresas, a atuação internacional é resultante dos esforços em pesquisa e desenvolvimento de novas tecnologias, o que diferencia as empresas estudadas dos demais casos de internacionalização tratados na literatura brasileira. Essa relação entre internacionalização e atividades de pesquisa e desenvolvimento é mais explorada na seção a seguir.

\subsection{O papel da tecnologia na internacionalização precoce de empresas brasileiras}

A análise do histórico das empresas estudadas possibilita a identificação de um importante aspecto comum: os três casos consideram a criação de novas tecnologias e aplicações como fator fundamental para o seu desenvolvimento.

Oficialmente inaugurada no ano de 1986, a Opto Eletrônica teve origem na oficina do laboratório de Física da Universidade de São Paulo em São Carlos. Da mesma maneira, a fundação da Bematech está relacionada com trabalhos acadêmicos. A empresa foi criada em 1990, porém seus fundadores já ocupavam uma sala na Incubadora Tecnológica de Curitiba (INTEC) desde o ano de 1989.

Mesmo tendo nascido distante dos centros universitários, a Lupatech é herdeira de um sistema industrial rico, com empresas ofertantes e demandantes de produtos e processos bastante densos em termos industriais e tecnológicos. A empresa surgiu em Caxias do Sul, cidade reconhecida como importante polo metalomecânico do País.

A análise geral do processo de internacionalização das empresas estudadas permite afirmar que os fundadores das três empresas analisadas consideram a atuação em mercados internacionais como essencial para o desenvolvimento das empresas.

As empresas Bematech, Lupatech e Opto Eletrônica passaram a desenvolver atividades de internacionalização comercial após, em média, nove anos desde a fundação. Portanto, quando comparadas com a maioria das grandes firmas brasileiras, essas empresas desenvolveram atividades de internacionalização em um curto período de tempo a partir das datas em que foram fundadas.

Com relação aos primeiros mercados conquistados por essas empresas no exterior, a Opto iniciou suas exportações na Itália, a Bematech exportou primeiramente para os Estados Unidos e a Lupatech para a Alemanha. As três empresas consideradas não iniciaram os processos de internacionalização comercial em países da América Latina, o que diverge do debate brasileiro sobre o tema. Esse aspecto também diverge dos pressupostos presentes no Modelo de Uppsala desenvolvido por Johanson \& Vahlne $(1977,1990)$. Segundo esse modelo, as exportações, na sua maioria, têm como destinos países mais próximos geográfica e culturalmente como forma de reduzir a "distância psíquica". Esse pressuposto não foi verificado entre as empresas estudadas.

As três empresas exportam para diferentes países. Para a Bematech, cerca de 7\% do faturamento total da empresa tem origem nas exportações; para a Opto e Lupatech, cerca de $20 \%$. Porém, a atuação em mercados internacionais através das exportações é entendida como uma das dimensões da internacionalização.

Com relação ao estabelecimento de subsidiárias comercias no exterior, as empresas estudadas estabeleceram suas primeiras subsidiárias comercias em países desenvolvidos: Opto e Bematech nos Estados Unidos e Lupatech na Alemanha. No caso da Opto, o primeiro mercado no exterior foi a Itália no ano de 1993. Somente após nove anos de sua primeira exportação, a empresa estabeleceu uma subsidiária comercial nos Estados Unidos e em seguida, no ano de 2003, a empresa desenvolveu subsidiárias comerciais na Austrália e na Áustria. Já a Bematech teve os Estados Unidos como o primeiro mercado no exterior. Depois de um ano da primeira exportação, em 2002, a empresa estabeleceu a primeira subsidiária comercial no exterior, também nos Estados Unidos. Por sua vez, a Lupatech estabeleceu sua primeira subsidiária comercial na Alemanha, que também foi o país de destino de sua primeira atividade de exportação. Em 
seguida, passou a contar com representantes comerciais na Itália e em Portugal. Para as empresas estudadas, o papel das subsidiárias comerciais não é apenas o fortalecimento do comércio, pois contribuem para os avanços tecnológicos alcançados pelas empresas e para o desenvolvimento das operações.

A análise do processo de internacionalização produtiva das empresas permite afirmar que para a Bematech a principal motivação para internacionalização é o acesso a insumos, componentes, peças e partes. Nesse contexto, para a expansão de suas atividades de produção no exterior, a empresa considera a aquisição de empresas que produzem hardware e software e que desenvolvem atividades de pesquisa. O objetivo da empresa é a complementação de sua oferta de equipamentos bem como o acesso a fornecedores.

Para a Lupatech, as motivações para a expansão internacional, a partir da aquisição de empresas no exterior, variam de acordo com o segmento de atuação. Nos segmentos em que a empresa já atua desde a sua fundação, definidos como Metal e Flow, o principal aspecto considerado nas decisões que envolvem o processo de aquisição de uma empresa relaciona-se com o mercado já desenvolvido. Ou seja, a Lupatech já domina a tecnologia para atuar nesses segmentos e, assim, tem interesse em adquirir o mercado desenvolvido pela empresa considerada.

Já em processos que envolvem a aquisição de empresas que atuam na produção de bens e serviços para a indústria de petróleo e gás, o principal fator considerado é o acesso a tecnologias já desenvolvidas pelas empresas consideradas. A estratégia de expansão da empresa complementa novas linhas de produtos e serviços com áreas de mercado adicionais, assegurando-lhe uma atuação ampla no mercado de petróleo e gás.

Apesar de a Opto Eletrônica ainda não desenvolver atividades de produção no exterior, a internacionalização produtiva já é considerada como uma estratégia para o crescimento futuro da empresa e para a expansão internacional de suas atividades. Assim, as principais motivações para internacionalização da Opto é o acesso a pesquisas e o fortalecimento da marca no exterior.

Desse modo, as empresas estudadas desenvolvem o processo de internacionalização focado em inovação tecnológica, conforme definido por Arbix et al. (2005), e as evidências empíricas podem ser analisadas a partir da dimensão tecnológica da internacionalização proposta por Chesnais (1996).

Para Hymer (1960), a inovação pode ser entendida como uma atividade que deve ser realizada constantemente pelas firmas, o que deve envolver o prolongamento do ciclo de vida dos produtos. Vernon (1966, 1979) também analisa a relação entre inovação e internacionalização na Teoria do Ciclo do Produto. Para o mesmo autor, as inovações desenvolvidas pela firma estão, inicialmente, voltadas para o atendimento do mercado doméstico. Nesse sentido, as empresas estudadas apresentam alguns pontos divergentes com as teorias clássicas, pois já consideram a atuação global desde a fundação e as atividades de P\&D estão focadas no desenvolvimento de produtos mundiais e de renovação constante.

A partir dos aspectos teóricos propostos por Dunning (1980), é possível afirmar que a aquisição de empresas no Brasil e no exterior pela Lupatech tem contribuído para o alcance de vantagens decorrentes da governança comum. A busca pela complementação da linha de produtos, especialmente para atuação no segmento Energy, tem facilitado o alcance de economias de escala e escopo e o acesso a recursos produtivos em termos mais favoráveis. A propriedade de ativos complementares também contribui para o desenvolvimento de vantagens competitivas. Ainda de acordo com Dunning (1980), a propriedade de ativos intangíveis pelas firmas contribui para o desenvolvimento de vantagens competitivas. Esse aspecto está presente nas três empresas estudadas.

Finalmente, as empresas estudadas podem ser analisadas a partir da consideração da internacionalização como uma das dimensões da diversificação, conceito desenvolvido a partir de Penrose (1956). A Opto Eletrônica tem desenvolvido produtos mundiais utilizando-se da mesma base tecnológica, o laser. Assim, a empresa tem a capacidade de desenvolver diversas aplicações para o laser entre as divisões da empresa: médica oftalmológica, odontológica, óptica, aeroespacial e industrial. Os produtos desenvolvidos a partir da mesma base tecnológica são negociados através das exportações, o que gera a diversificação de mercados geográficos.

A Bematech também utiliza a base tecnológica criada inicialmente para a produção de impressoras de telex e tem desenvolvido novas aplicações em automação comercial. A aquisição de empresas no Brasil e no exterior tem contribuído para a criação de novas competências e desenvolvimento de novas aplicações destinadas, inclusive, a mercados internacionais. Como resultado, a empresa tem sido capaz de fornecer um pacote completo a seus clientes, o que pode ser entendido inclusive como uma maneira de se proteger da concorrência local e internacional.

Por sua vez, a Lupatech tem alcançado a diversificação de produtos e serviços por meio da aquisição de empresas no Brasil e no exterior. Especialmente no segmento Energy, as novas tecnologias adquiridas favorecem o desenvolvimento de produtos e serviços facilmente adaptáveis, de acordo com o mercado em que a empresa atua. A diversificação por meio da aquisição de empresas também pode ser entendida como uma maneira de se proteger da concorrência. Finalmente, a partir dessas considerações é possível desenvolver a conclusão para este estudo. 


\section{Conclusão}

Este estudo procura preencher uma lacuna na literatura, relacionada ao entendimento das principais razões que levam a uma trajetória diferenciada para empresas brasileiras, a saber: uma internacionalização que pode ser considerada precoce para os padrões brasileiros. O processo de análise considerou desde aspectos relacionados à fundação das empresas até dados sobre o desempenho atual, com o objetivo de identificar os pontos convergentes e divergentes entre as empresas estudadas e o debate no âmbito das empresas nacionais.

A análise das evidências empíricas encontradas em pesquisa de campo suporta a decisão pela confirmação da primeira proposição. As três empresas estudadas atuam em mercados em que a renovação dos produtos é acelerada e desenvolvem produtos com um olhar que vai além do mercado brasileiro. Por isso, os investimentos contínuos em atividades de pesquisa e desenvolvimento, bem como o acompanhamento das tendências nos setores em que atuam, são fundamentais para a continuidade de suas atividades.

A renovação acelerada dos produtos requer investimentos em atividades de pesquisa e desenvolvimento continuamente. Essas atividades são desenvolvidas em laboratórios concentrados principalmente no Brasil e, desde o início, são consideradas fundamentais para o crescimento e desenvolvimento das empresas.

Do mesmo modo, as evidências obtidas em campo suportam a segunda proposição. Verificou-se que as empresas estudadas iniciaram o processo de internacionalização precocemente, dado que a dimensão comercial da internacionalização, por meio das exportações, foi iniciada nas empresas Opto Eletrônica, Bematech e Lupatech, respectivamente, com 8,11 e 8 anos de fundadas. Portanto, quando comparadas com a maioria das grandes empresas brasileiras consideradas na literatura, essas empresas se internacionalizaram poucos anos após a sua fundação, ao contrário das grandes empresas que podem ser classificadas como de internacionalização tardia. As três empresas consideram a criação de novas tecnologias e aplicações como elemento central para a expansão e desenvolvimento desde o início das atividades.

As empresas estudadas foram fundadas entre as décadas de 1980 e 1990: a Lupatech em 1980, a Opto Eletrônica em 1986 e a Bematech em 1990. Esse período foi marcado por alterações importantes entre as variáveis macroeconômicas, como taxas de câmbio, juros e inflação. Porém, as empresas estudadas foram impactadas de maneiras diferenciadas.

Não foram encontradas, contudo, evidências empíricas capazes de suportar a terceira proposição. Verificou-se, na pesquisa de campo, que, desde o início das atividades que originaram as empresas, seus fundadores já consideravam a atuação global como fator fundamental para seu desenvolvimento. As primeiras subsidiárias comerciais no exterior foram estabelecidas em países desenvolvidos: Opto e Bematech nos Estados Unidos e Lupatech na Alemanha. Esse é um aspecto divergente quando se comparam as empresas estudadas com as demais brasileiras, que buscaram países da América Latina para o estabelecimento inicial das atividades de exportação. Ainda, em decorrência da forte presença exportadora, a maioria das empresas brasileiras realizaram Investimentos Diretos no Exterior também em países da América Latina.

As subsidiárias comerciais não tinham apenas a função de intensificação do comércio. Elas também contribuíram para os avanços tecnológicos das empresas. Ainda, as empresas estudadas não iniciaram a internacionalização comercial em países da América do Sul. Quanto à internacionalização produtiva, apenas a Lupatech tem forte presença na Argentina, devido às características do segmento de energia em que a empresa atua.

É importante destacar que a análise do processo de internacionalização da Opto Eletrônica, da Bematech e da Lupatech demonstra que elas não seguem a trajetória comum de internacionalização das empresas brasileiras uma vez que atuam em um segmento diferenciado, baseado no desenvolvimento de novas tecnologias e novas aplicações. Esse é o principal aspecto que as diferencia da maioria das empresas brasileiras tendo, portanto, impactos importantes na trajetória de internacionalização das empresas.

Finalmente, a trajetória de internacionalização das empresas estudadas demonstra a existência de um elemento de reforço entre três importantes aspectos: a base tecnológica de cada empresa, o dinamismo tecnológico nos mercados em que atuam e a necessidade de internacionalização das atividades. Esses fatores se alimentam, ou seja, o desenvolvimento contínuo de novos ativos tecnológicos estimula, reforça e requer a presença internacional dessas empresas.

\section{Referências}

Andrade, A. M. F., \& Galina, S. V. R. (2013). Efeitos da Internacionalização sobre o desempenho de multinacionais de economias em desenvolvimento. Revista de Administração Contemporânea, 17(2), 239-262.

Arbix, G., Salerno, M. S., \& De Negri, J. A. (2005). O impacto da internacionalização com foco em inovação tecnológica sobre as exportações brasileiras. Revista de Ciências Sociais, 48(1), 395-442.

Barreto, A., \& Rocha, A. (2003). A expansão das fronteiras: brasileiros no exterior. In A. Rocha (Org.), As novas fronteiras: a multinacionalização das empresas brasileiras. Rio de Janeiro: Editora Mauad.

Cantwell, J. (1989). Technological innovation and multinational corporations. Oxford: Basil Blackwell. 
Cantwell, J., \& Piscitello, L. (1999). Corporate diversification, internationalization and location of technological activities by MNCs: differences between EU and non-EU firms in the european regions (Dynacom Series, pp. 1-28). Italian: Laboratory of Economics and Management.

Chesnais, F. (1996). A mundialização do capital. São Paulo: Xamã. 336 p.

Coutinho, L., Hiratuka, C., \& Sabbatini, R. (2008). $\mathrm{O}$ investimento direto no exterior como alavanca dinamizadora da economia brasileira. In O. Barros \& F. Giambiagi (Orgs.), Brasil globalizado (pp. 63-85). Rio de Janeiro: Campus.

Cyrino, A. B., Oliveira, M. M., Jr., \& Barcellos, E. P. (2010). Evidências sobre a Internacionalização de Empresas Brasileiras. In M. M. Oliveira Jr. (Org.), Multinacionais brasileiras. (pp. 93-109). Porto Alegre: Bookman.

Dunning, J. H. (1980). Toward an eclectic theory of international production: some empirical tests. Journal of International Business Studies, 11(1), 9-31.

Dunning, J. H. (1993). The globalization of business. London: Routledge.

Dunning, J. H. (1997). Alliance capitalism and global business. London: Routledge.

Fleury, A., \& Fleury, M. T. L. (2007). Internacionalização das Empresas Brasileiras: em busca de uma abordagem teórica para os late movers. In A. Fleury \& M. T. L. Fleury (Orgs.), Internacionalização e os países emergentes (pp. 3-13). São Paulo: Atlas.

Goldbaum, S. (2001). Estudo de caso 1: bematech indústria e comércio de equipamentos eletrônicos. In G. Oliveira (Org.), Empresas tecnológicas. Estudos de casos: Bematech, Biobrás, Optoeletrônica (pp. 4-15). São Paulo: Fundap.

Hymer, S. (1960). The International operations of national firms: a study of direct investment. Cambridge: MIT Press. 236 p.

Hymer, S. (1983). Empresas multinacionais: a internacionalização do capital (2 ed.). Rio de Janeiro: Graal. 118 p.

Instituto Brasileiro de Geografia e Estatística - IBGE (2005). Empresas industriais de alta intensidade tecnológica têm receita e investimento acima da média. Recuperado em 03 de março de 2010, de http://cod.ibge.gov.br/1yglk.

Johanson, J., \& Vahlne, J. E. (1977). The internationalization processo $f$ the firm - a model of knowledge development and increasing foreign market commitments. Journal of International Business Studies, 8(1), 23-32.

Johanson, J., \& Vahlne, J. E. (1990). The mechanism of internationalisation. International Marketing Review, 7(4), 11-24. http://dx.doi.org/10.1108/02651339010137414.

Knight, G., \& Cavusgil, T. (2004). Innovation, organizational capabilities and the born global firm. Journal of International Business Studies, 35(2), 124-141.

Laplane, M., \& Sarti, F. (1999). Investimento direto estrangeiro e o impacto na balança comercial (Texto para Discussão, 629). Brasília: IPEA.

Madsen, T. K., \& Servais, P. (1997). The internationalization of born globals: an evolutionary process? International Business Review, 6(6), 561-583.

Penrose, E. (1956). The theory of the growth of the firm. Oxford: Oxford University.

Ribeiro, M. P. (2001). Estudo de caso 3: Opto Eletrônica S/A. In G. Oliveira (Org.), Empresas tecnológicas. Estudos de casos: Bematech, Biobrás, Optoeletrônica (pp. 35-51). São Paulo: Fundap.

Ricupero, R., \& Barreto, F. M. (2007). A importância do investimento direto estrangeiro do Brasil no exterior para o desenvolvimento socioeconômico do país. In A. Almeida (Org.), Internacionalização de empresas brasileiras: perspectivas e riscos (pp. 1-36). Rio de Janeiro: Elsevier.

Rocha, A., Silva, J. F., \& Carneiro, J. (2007). Expansão internacional das empresas brasileiras: revisão e síntese. In A. Fleury \& M. T. L. Fleury (Orgs.), Internacionalização e os países emergentes (pp. 184-193). São Paulo: Atlas.

Silva, M. L. (2003). A inserção internacional das grandes empresas nacionais. In M. Laplane, L. Coutinho \& C. Hiratuka (Orgs.), Internacionalização e desenvolvimento da indústria no Brasil (pp. 105-163). São Paulo: UNESP.

Vahlne, J., \& Johanson, J. (2013). The uppsala model on evolution of the multinational business enterprise - from internalization to coordination of networks. International Marketing Review, 30(3), 189-210.

Vernon, R. (1966). International investment and international trade in the product cycle. The Quartely Journal of Economics, 80(2), 190-207.

Vernon, R. (1979). The product cycle hypothesis in a new international environment. Oxford Bulletin of Economics and Statistics, 41(4), 255-267. http://dx.doi. org/10.1111/j.1468-0084.1979.mp41004002.x. 